\title{
IMPACT OF FINANCIAL CONSTRAINTS AND GENDER DISPARITIES ON FEMALE'S HIGHER EDUCATION (A CASE STUDY OF DISTRICT SWABI, KPK, PAKISTAN)
}

\author{
Gulzar Ali \\ Assistant Professor, Department of Economics, \\ Islamia College University Peshawar, KPK, Pakistan \\ gulzaricup@yahoo.com \\ Shaista Khan \\ Lecturer, Department of Economics, \\ Kohat University of Science \& Technology, Kohat, KPK, Pakistan \\ Said Zamin Shah \\ Assistant Professor, Department of Economics, \\ Islamia College University Peshawar, KPK, Pakistan
}

\begin{abstract}
There are different factors that adversely affect the female's education in different areas of Pakistan, however in this study two important factors are investigated, that it has any effect on female's higher education in District Swabi (KPK, Pakistan). Firstly, the financial constraints that most parents/guardians face have any discouraging effect on the female's higher education in Swabi District? Secondly, that the higher education of females adversely affected by gender disparities in District Swabi? The findings of this study indicate that majority of the parents in the study area supports and happily bear the expenses of higher education of their daughters though it is very hard for them. Further, the study concludes that though up to a greater extent the gender inequalities have been minimized, however, still exist especially in rural areas where sometimes parents prefer males higher education over females.
\end{abstract}

Keywords: Financial Constraints; Gender Disparities; Importance of Daughter Education

JEL Code: H52, I2, I22, J11

\section{INTRODUCTION}

To conquer the cruel conventions and customs that may refute the image of young ladies and females, the best tool is education (Khan, 2007). Human economic development and advancement is just conceivable in such circumstances where both gender (males and females) are profoundly educated and skilled. Unfortunately, the involvement and enrolment of females to obtained higher education and in labor force in developing countries as well as in Pakistan is regrettably less (Qureshi et al., 2007).

The higher education has a key role in making and creating the scientists, economist, political leaders, philosophers, professionals, doctors, engineers, social and religious scholars, who offer their services to serve the general public, societies and the countries. In this modern era females aims and wishes to equally contribute, but one of the main problems with females in Pakistan that their access to higher education is very low due to gender disparities that mainly arise from the financial Constraints especially faced by parents in rural areas (Madhani, 2007; Haider, 2008). In order to make itself more profitable from worldwide global economy the developing countries needs to give special attention and importance to female's higher education (World Bank, 2010).

Various parents have stressed for the financial constraints that are facing by poor and lowincome families especially providing the higher education. Moreover, the working conditions of the parents/guardians as well as the socio-economic conditions that affect the female's higher education. The utilizing of gender disparities gap in Pakistan is also one of the main causes besides financial constraints that adversely affect the female's higher education. Moreover, the participation of females in Pakistan in other economic activities as well as in labor force is very minimum as compared to 
developed and emerging countries (Jejeebhoy \& Sathar, 2001; Grunenfelder, 2012), though approximately half of the population of Pakistan is consists of females.

Presently with the headway of human culture and a more extensive vision about women, females of developed nations have significantly contributed to their countries in economic, political, social and cultural condition (Suen, 2013). However, in Pakistan females are as yet denied of their privilege and have constrained open doors in various different backgrounds. Their position and status are also considered as low as compared to men. Female education is the sole element to make them proficient and successful in daily life (Jamal, 2014).

It has been observed that females were disregarded in the past in many important issues. One noteworthy ramifications of disregarding females are that they have not benefitted from higher education that creates new abilities and improved the personnel skills of the women's. Though these all facilities are available and provided to men. Male and female are essential part of one another throughout everyday life and it may not be worth saying that society is fragmented with both of them. The female takes part with her accomplice in living, passing life and battling for betterment of their families.

\section{Research Questions}

The main objective of this study is to investigate the behavior of parents/guardians towards female's higher education in District Swabi (KPK, Pakistan). In order to address this phenomenon, the following research questions to be investigated:

1. Do the financial constraints affect the female's higher education in District Swabi (KPK, Pakistan)?

2. Can gender specification affect female's education, especially in District Swabi (KPK, Pakistan)?

\section{REVIEW OF LITERATURE}

Everybody has now recognized that female higher education is very significant and essential for family, society and country. Now days the social activist, political leaders, policy makers and government bodies doing their best efforts and promote females higher education. For that purpose, government of Pakistan has announced and launched different education strategies, programs and schemes to improve female's education. However, the hole is still existed in achieving the fruitful goal (Malik, 2014).

\section{Literature on Financial Constraints and Importance of Females Education}

The importance of education has been discussed and interpreted by various researchers and academic managers in different ways; however, all are agreed that education has great importance to all individuals across the globe. Some of the analysts refer education as societal change as well as development of thinking and mind that mainly took place with cooperation of educational institution situated in the territory. In realities the change and advancement in societies are solely depended upon the feasibility of education framework and the ration of individuals. In this regard the role of female to obtained higher education and plays their essential job in improvement of a country, society and its family is very critical (Ray, 2000; Psacharopoulos \& Patrinos, 2002).

According to (Henard \& Roseveare, 2012; Haider, 2008) the female higher education in Pakistan were very low as compared to other developing and most of the Asian countries. The standard of education is also stumpy and large number of young females are generally keen and able enough to get higher education, yet denied due to the diverse cultural, financial and social and constraints that leads to their undesirable dynamic job in the improvement of society. However, the higher education will able the females in Pakistan to play their vital part in the improvement of society and for development of the country (Malik, 2005).

Samina and Kathy (2011) emphasized that higher educated females have critical part in development of socio-economic conditions and also improving the status of human capital. According (Sadia and William, 2015) the advanced education enable females to explore their capabilities and to deliver their major role even in general public and set an example for other especially for young females through obtaining higher education. However, sometimes the financial Constraints adversely affect the females higher that restrain them. The higher education helps the even the deprived females to explore their abilities and take part in making various strategies related to social, cultural and financial issues matters as well as support and guides their families in these matters (Zafar et al., 
2005). Unfortunately, majority of the families relentlessly ignored their females to get higher education in Pakistan due to the financial constraints. The female higher education rate especially in rural areas are very low and most of the families favoring men over ladies in providing the higher education due to the existence of the financial problems that were facing most of the families of rural areas. Females have constrained chances to get advanced education and lead to gender discrimination especially in the field of higher education due to heavy financial burden (Ejaz et al., 2015).

Rafiq et al., (2013) analyzed that due to financial constraints, gender disparities and coeducation also adversely affect the females higher education in rural areas, where parents feel hesitation to send their daughters to mixed gender schools, despite of the fact that they are in favor of education. Aezaz and Kemal (2012) disparately found in their study that 52.3\% of parents thinking that higher educated girls became rebellious to traditional roles and due to rebellious educated females, the family's respect could be destroyed. In rural areas of Punjab preference is given to sons as they are heirs of family due to the financial constraints of most of the families. Shahzad et al., (2011) found due rapid changes in the world regarding the status and education of females, most family head in Pakistan were also excited about sending their daughters and girls for higher education yet they couldn't do accordingly due to financial status of the family. Huge reason of young woman's dropout was poverty, early age marriages and gender preferences due to financial constraints (Chaudhry \& Rahman, 2009). The main components of restricting the females from higher education were seen to be poverty, nonappearance of care or inspiring powers, uneducated family head and early social associations. A lot of the family head were pleasant to empower the females to do assignments (Andres \& Chavez, 2015).

\section{Literature on Gender Discrimination and Female's Education}

One of the main reasons that adversely affect the female's higher education is gender discrimination that mainly exits within families. Coleman (2007) highlighted that aside from other reason low female education is due to high gender discrimination that exists in Pakistani culture. Undeniably those societies are less developed where gender gap exits in greater extent as compared to lower extent. To remove or minimize the gender disparities a strong base of moderate society with contentment of healthy environment for female education and moderate values of culture is needed.

It is a hard reality that gender discrimination exits in Pakistan especially in rural areas where the level of education is not satisfactory. It will be fundamental for Pakistan to utilize the abilities of everyone especially of women. Obtaining of higher education open the doors for young females to furnish themselves with the abilities to contribute more completely to society and in the development of their country (Bushra, 2014; Sofia, 2015). UNICEF (2006) recommended in their survey reports that despite of the facts that gender discrimination exits in Pakistan, however, providing basic and higher education to females will makes them able to contribute to the serve their family, society and country. Education brings personnel confidence especially in females which is a key fixing in empowering a person's full interest in the private and public arena. No doubt that gender discriminations holes in Pakistan starts at home, with young men being esteemed over young ladies in all regards during their childhood (Haque, 2002).

Samina and Kathy (2011) concluded from their study that gender disparities and biased attitudes of parents towards their daughter limited the available opportunities to females in Pakistan. Further, demonstrates that parental frames of mind in Pakistan are the main hurdles in the way of females to take an interest in informal organizations. Ladies in Pakistan are liable to a variety of social and mental hindrances that confinement their portability and keep them away from utilizing their common capabilities. Bukhari and Ramzan (2013) examined that gender disparities badly effects the societal environment in Pakistan to an extremely huge degree. Since females have for the most part been subject to confinements all through their childhood, when they need to attend basic and higher education, improves and developed their abilities, and able themselves to contribute to society and their family. Sofia (2015) highlighted that there are signs that ladies are empowered to add to society and to their families financially in considerable and applicable ways. With the changes of biased attitudes towards female's higher education and thus societal standards at present structure the most grounded hindrance is rapidly changing, and women are taking part to contribute both in formal and informal sectors. Sumera et al., (2018) added that due to parental education their attitudes towards educated daughter are rapidly changing and their substantial decrease in gender discrimination. The educated parents give worth to their daughter opinion, respects their views, get suggestions from them 
while taking an important decision that gives confidence to the females to serve their family and society. This resembles an upward winding, bringing about more noteworthy open doors for females to fully participate in all parts of life.

Ashraf (2007) addressed that gender disparities were also exists even in professional fields in Pakistan. He concluded that female teachers working in Northern Areas of Pakistan facing huge number of gender discrimination. He further added that despite of the fact these educated women's and knows their rights and responsibilities and have profound established social standards but still they are greatly affected by gender discrimination. Grunenfelder (2012) concluded that provision of higher education will enable females in Pakistan to defeat gender discrimination and enable themselves to play a more prominent job within the family and in societal levels too. The finding of the studies showed that $79 \%$ of the high educated women expressed that they had reinforced their purpose towards satisfying different duties within the family and at working place. Awan (2016) highlighted the significance of female's education to family and society. The study concluded that education empowers ladies to plays an imperative role at numerous levels. The higher education transforms their personnel, social and professional life that greatly benefits their close family, the more extensive family, companions, society and the entire community.

Naz et al., (2013) investigated that how educated females in Pakistan are treated in respected way. The study found that women especially in rural areas been affected up to some extent of gender discrimination. However, the parental attitudes became positive towards the females education. This generously builds a lady's self-esteem, which has a spiraling beneficial outcome on her creating way of life as an acknowledged and dynamic individual from society, where already they were disregarded, now they are being respected, much worth has been now given to their opinions and thus they can add to the prosperity of their family. Ahmad (2001) conducted study on the South Asian females living in the United Kingdom and concluded that higher education creates trust and confidence in their capabilities while at the same time reinforcing their social, religious and individual personalities. It is essential that higher education exhibits same outcome inside Pakistan.

\section{METHODOLOGY}

\section{Conceptual Framework}

In figure 1 the brief framework of this research investigation is illustrated. As per the studies of (Khan, 2007; Ali et al., 2011, Bukhari \& Ramzan, 2013; Sofia, 2015) in rural areas of Pakistan the higher gender disparities exists that have an adverse and discouraging effect on females higher education. In this analysis the effect of financial constraints and gender disparities has been investigated to examine its effect on female's higher education, that have crucial role in sending their daughters for obtaining education in higher institution. The framework of this investigation designed in such a manner that the financial constraints and gender disparities effects the importance of females education that leads to the parental decision that either their daughters continue and obtained higher education or not. The researchers of this study consider that if parents/guardians know the importance of higher education, they will decide in favor of their daughter's higher education irrespective of the financial expenses. Further, if the gender disparity exits in greater extent, it may have discouraged effect of daughter's higher education.

\section{Figure No. 1 Conceptual Framework}

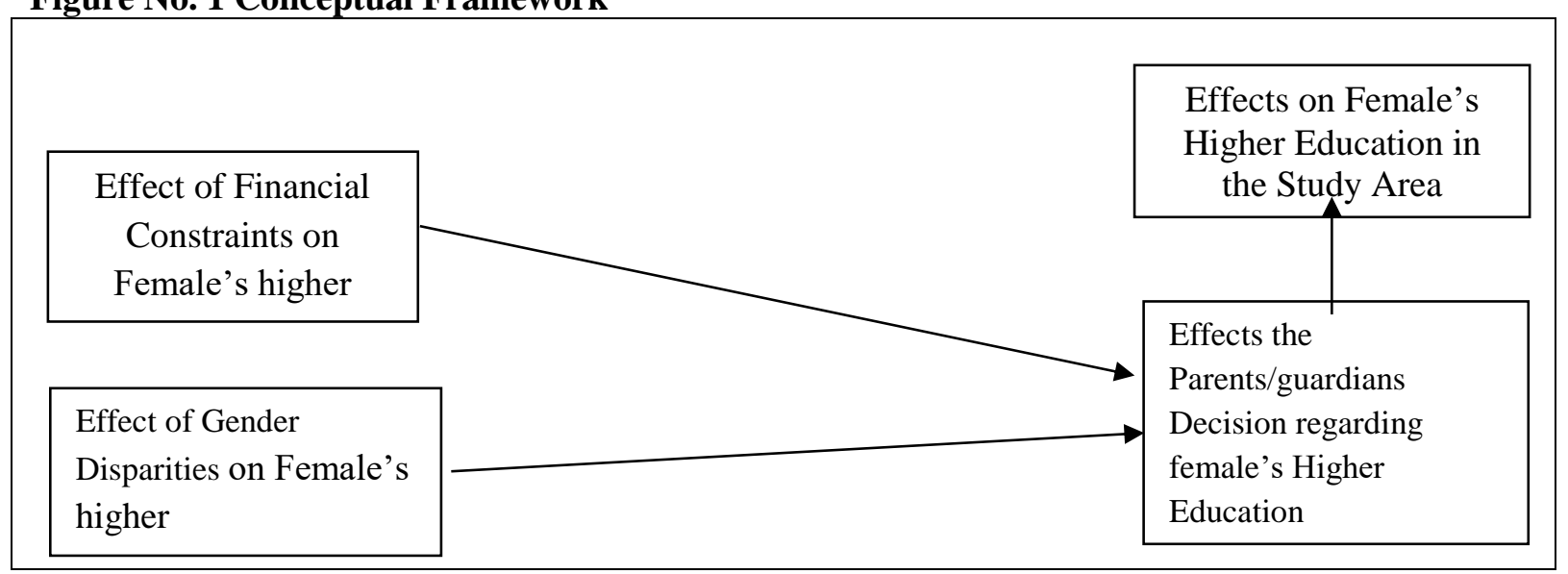


In figure 2 the details framework design is illustrated. After the brief introduction and significance, the research questions been developed in the light of past studies examination.

\section{Figure No. 2 Research Design of this Study}

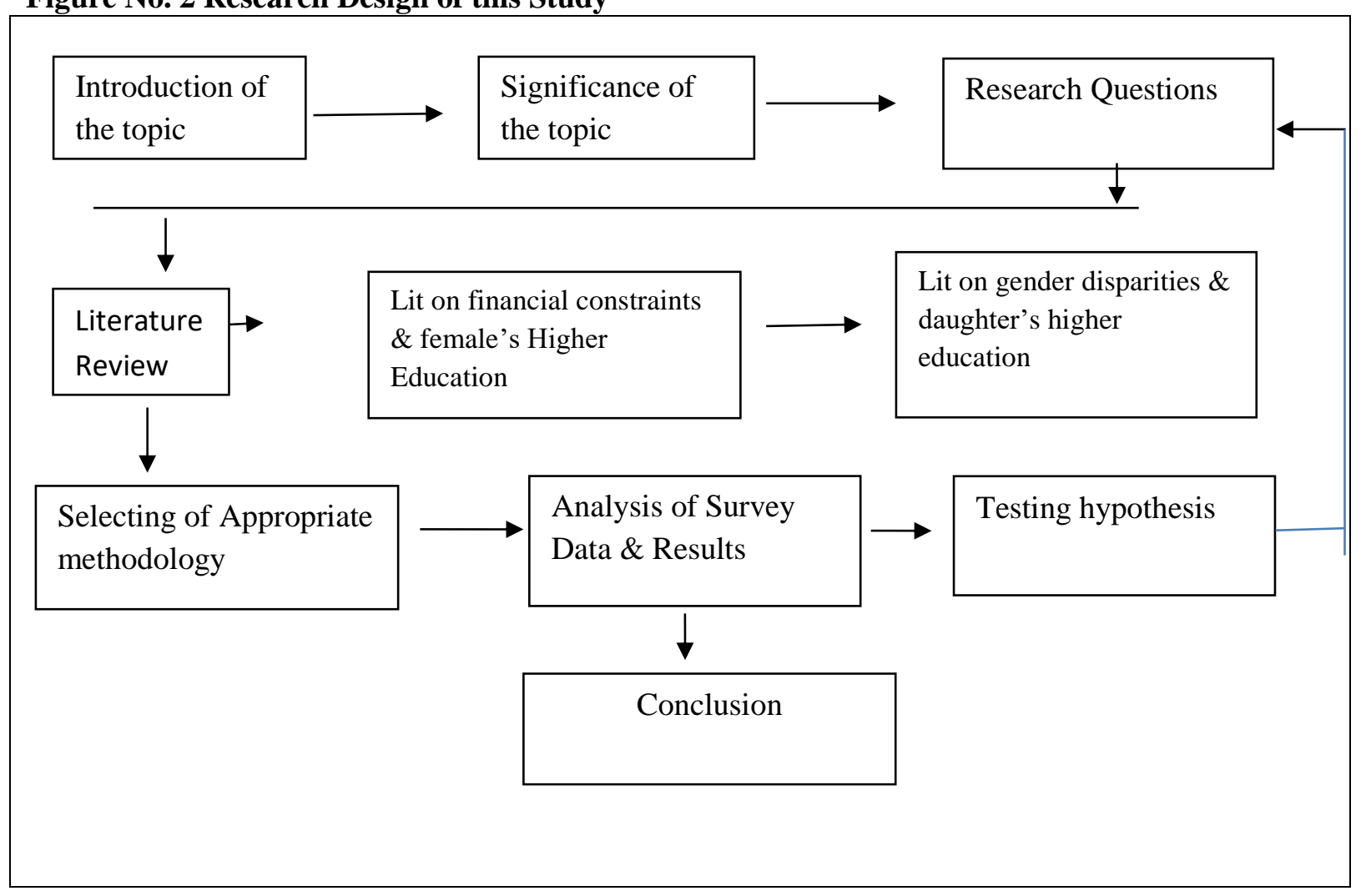

\section{Methodology and Data Collection}

To examine the attitudes of parents while perceiving higher education of daughters, 850 questionnaires were distributed and filled from the female's students who are the students of intermediate, studying in different government colleges of District Swabi (KPK, Pakistan). The rationale behind for filling the questionnaire from intermediate students were that as these females will enroll themself and get higher education if allowed by their parents / guardians. The survey was conducted during October-November 2019 and data was collected through questionnaire selection simple random techniques. After collecting the filled questionnaire, 820 questionnaire data were included in this study while rests of the questionnaires were dropped as found inappropriate.

\section{ANALYSIS AND DISCUSSION}

\section{Analysis of the Effect of Financial Constraints on Female's Education}

In this $21^{\text {st }}$ century, female's education is very essential for the improvement of society. Regardless of numerous worldwide developments objective, female's education is one of the focused areas now a days for all countries. At present all are very much aware of the importance of female higher education as well as of wide scope of issues that are facing now days. For quite a while, it has been experiencing a profound emergency - on one hand, advanced education organizations, institution, particularly colleges and universities are compelled to legitimize their rules to facilitate the female education. On the other, advanced education institution and rural families facing severe financial crises that influencing the higher education particularly through monetary conditions. Today, as we begin the most recent decade of the twentieth century, we can most likely say that the issues of female education are still perceived and well comprehended. However, sufficient arrangements are as yet deficient.

The details analysis of the responded responses on the importance of parent's attitudes on daughter higher education in the study area is illustrated in below table (1). 
Table No. 1: Respondents Analysis on the Importance of Daughter Education

\begin{tabular}{|l|c|c|c|c|}
\hline Statement & $\begin{array}{c}\text { Strongly } \\
\text { Disagree }\end{array}$ & Disagree & Agree & $\begin{array}{c}\text { Strongly } \\
\text { Agree }\end{array}$ \\
\cline { 2 - 5 } & 1 & 2 & 3 & 4 \\
\hline $\begin{array}{l}\text { Do your parents/guardians will allows to obtain higher } \\
\text { education despite of the financial Constraints? }\end{array}$ & $4 \%$ & $9 \%$ & $35 \%$ & $52 \%$ \\
\hline $\begin{array}{l}\text { Do your parents/guardians have a supportive attitude } \\
\text { to pay all the expenses of higher education? }\end{array}$ & $6 \%$ & $11 \%$ & $24 \%$ & $60 \%$ \\
\hline $\begin{array}{l}\text { Do your parents/guardians give attention on your } \\
\text { education rather than expenses? }\end{array}$ & $9 \%$ & $13 \%$ & $33 \%$ & $45 \%$ \\
\hline $\begin{array}{l}\text { Does the expenses of higher education are burden on } \\
\text { your parents/guardians? }\end{array}$ & $3 \%$ & $5 \%$ & $32 \%$ & $60 \%$ \\
\hline $\begin{array}{l}\text { Do you parents appreciate your well achievements in } \\
\text { education? }\end{array}$ & $0 \%$ & $0 \%$ & $30 \%$ & $70 \%$ \\
\hline $\begin{array}{l}\text { Do your parents/guardians encourage you for getting } \\
\text { higher education irrespective of the expenses? }\end{array}$ & $5 \%$ & $13 \%$ & $34 \%$ & $48 \%$ \\
\hline Average & $4 \%$ & $9 \%$ & $32 \%$ & $55 \%$ \\
\hline
\end{tabular}

Improving female's education in developing countries is a perplexing issue. There are numerous external and internal factors responsible for this important arena and one of the important factors is of financial situation of parents/guardians and families especially in rural areas. Without instructing the female populace, accomplishment of better and higher standard of life, improvement of society and development of a nation that is impossible without female's higher education. To examine the effect of financial constraints on female higher education, different questions were asked through a questionnaire from approximately 540 respondents.

The study found that in the study area the parents/guardians know the importance of education and allow their females children's for obtaining higher despite of their financial constraints. Responding to the question that "Do your parents/guardians will allows to obtain higher education despite of the financial Constraints?" 59\% of the respondents were seemed highly satisfied, 35\% were satisfied and $13 \%$ of the respondents seemed disagree that their parents can allows that to get higher education irrespective of the high education expenditure.

Asking the question that was asked in the questionnaire that "Do your parents/guardians have a supportive attitude to pay all the expenses of higher education?" the $60 \%$ respondents seemed highly satisfied from their parents/guardians attitude while bearing the expenses of their females education, $24 \%$ are satisfied which means that the parents happily allow their daughters to obtain higher education.

From the analysis given in table (1) it can be concluded that parents attitude towards their daughter education is very moderate and they wants that their daughter gain higher education in the study area as in response of question that "Do your parents/guardians give attention on your education rather than expenses?" $45 \%$ of the respondents viewed that their parents gave attention to obtain higher education rather than consideration of expenses of higher education, 33\% respondents are satisfied that means that the parents of $78 \%$ respondents gave weightage and importance to higher education.

The result of table (1) reveals that parental attitudes towards daughter education are progressive and encouraging as the respondent's replies are very substantial to the questions like "Does the expenses of higher education are burden on your parents/guardians?" $92 \%$ of the respondents viewed that their higher education expenses are burden on their parents/parents. However, besides that most of the parents happily bear the expenses and aims that their daughters gain higher education.

From the overall analysis given in table (1) it can be concluded that the parents in the study area are well aware of the importance of higher education and believes that attaining higher education is essential for their daughter in this $21^{\text {st }}$ century that will enables them to actively participate and take part in improving the wellbeing of their families, societies and country. The advocates of conventional 
thoughts regarding the females education there is need of proper awareness in parents especially in rural areas. In short educating females will strengthening them and higher education will shape the level of opportunities achieved.

\section{To examine the Effect of Gender Discrimination on Female's Education}

The gender discrimination and disparities lie more in less developed and developing countries as compared to developed countries. Pakistan being the developing country, some sort of gender discrimination exits especially in rural areas. Coleman (2007) argued that aside from any ethical and moral contemplation, the factor that drive towards disposing of the gender inequalities possessed in culture of Pakistani culture, needs a strong foundation of a dynamic municipal society and the fulfillment of more noteworthy education especially in females as well as moderate values of culture. Undeniably those societies in are lees developed where gender gap exits in greater extent as compared to lower extent. In order to minimize the gender disparities in Pakistan, it is the sole responsibility of every Pakistani citizen to play its role in this regard. That will not only open doors for females but will also provide an opportunity to furnish them with the abilities and to contribute more precisely to society and country. Moreover, elimination of gender discrimination enables them to connect in community and in improve the financial matters.

No doubt that attitude of parents plays an imperative role in gender discrimination that not only restricts the role of females but also minimize the opportunities for females to explore themselves in a right and equal ways. Females in Pakistan are liable to a variety of social and mental hindrances that confinement their abilities and restrict them to play their role in public arena. Therefore, in this study it is attempted to examine the gender discrimination in the study area. For that purpose, different questions are included in the questionnaire that has been distributed among the various girls. After filling and collecting the questionnaire, the data has been sorted for further use. The details of provided information and their results analysis for gender discrimination are given in below table (2).

Table No. 2 Respondents Analysis on Gender Discrimination \& Higher Education

\begin{tabular}{|l|c|c|c|c|}
\hline statement & $\begin{array}{c}\text { Strongly } \\
\text { Disagree }\end{array}$ & Disagree & Agree & $\begin{array}{c}\text { Strongly } \\
\text { Agree }\end{array}$ \\
\cline { 2 - 5 } & 1 & 2 & 3 & 4 \\
\hline $\begin{array}{l}\text { Do parents/guardians allow you in co-education } \\
\text { system to obtain higher education? }\end{array}$ & $8 \%$ & $13 \%$ & $43 \%$ & $36 \%$ \\
\hline $\begin{array}{l}\text { Do parents/guardians give equal opportunities } \\
\text { irrespective of the gender? }\end{array}$ & $11 \%$ & $16 \%$ & $39 \%$ & $34 \%$ \\
\hline $\begin{array}{l}\text { Do parents/guardians have same preferences of } \\
\text { education irrespective of gender discrimination? }\end{array}$ & $9 \%$ & $10 \%$ & $46 \%$ & $35 \%$ \\
\hline $\begin{array}{l}\text { Do parents/guardians have same education } \\
\text { expenditure preferences irrespective of the gender? }\end{array}$ & $13 \%$ & $22 \%$ & $36 \%$ & $29 \%$ \\
\hline Average & $10 \%$ & $15 \%$ & $41 \%$ & $34 \%$ \\
\hline
\end{tabular}

In order to examine the gender disparities in the study area various question were asked from females students studying in different colleges in district Swabi. From the respondents responses it is concluded that gender disparities still exist up to some level besides of this new technological, media and much awareness area. Though majority of the female's students were of the view that they didn't face any sort of gender disparities, but some of the female's students didn't deny the fact of gender discrimination exits in education system of Pakistan. The analysis of table (2) shows that approximately $31 \%$ of the females in the study area agreed that they are facing gender discrimination up to certain extent in different forms. However, on the basis of that it may be concluded that the ration in overall Pakistan may more of that especially in the rural areas.

In response to the co-education system, $21 \%$ of the respondents gave their view that their parents/guardians were not in favor to send them in gender mixed education system, though they are well aware of the importance of female's education. However, $79 \%$ of the females respondents viewed that their parents allow them to get higher education even in co-education system. 
The question asked regarding the education preferences and equal opportunities, their responses were varying. In response to the question "Do parents/guardians give equal opportunities irrespective of the gender?" $27 \%$ of the females seems dis-satisfied and expressed the sign of gender discrimination despite of the fact that majority of the females students denied gender disparities as $34 \%$ highly satisfied while 39\% are satisfied that they are provided and given the same opportunities as provided to males in their family. Another questioned that was asked about the "equal preferences of education irrespective of gender", the $81 \%$ of females were viewed that their parents/guardians provide and give them equal preferences to enroll and get higher education as like males. However, $19 \%$ of the females respondents showed their concern regarding the equal preferences regarding higher education and seemed dis-satisfied that shows that these respondents were faced some sort of gender discrimination and responded that they didn't provide equal preferences like males.

Regarding the question of income expenditure on education most of the respondents expressed higher gender discrimination in this regard. The 35\% of the females respondents responded that their parents/guardians preferred to bear the education expenditure of males over females and their/guardians parents didn't spend equal amount of money on the education of their brothers and her. It means that males are given preference over females and it's a sign of gender disparity. However, 29\% strongly agree and 36\% of the respondent are viewed that their parents/guardians didn't do any sort of discrimination and equally bear and spend on higher education irrespective of the gender discrimination.

\section{CONCLUSION}

From the analysis of this study, it is concluded that though parents especially in the study area knows the importance of female's education and also keenly interested to enroll and provide higher education to their daughters. However, due to the financial constraints and income status of some families the higher education of some of the females was adversely affected. Moreover, it can also be concluded from the findings of the study that besides the financial constraints and burden of the higher education expenses most of the parents/guardians were very positive towards getting of higher education and keenly interested to provide many opportunities to their daughters in order to get higher education.

The past literature (i.e., Coleman, 2007; Samina \& Kathy; 2011; Bushra, 2014; Sofia, 2015) addressed that gender discrimination existed in Pakistan and expressed deep concerns and concluded that gender discrimination exits in societies of Pakistan that adversely effects the females education in Pakistan. The findings of this study also indicates that though up to greater extent the gender inequalities have been minimized in the study area, however, still it is exits especially in rural areas of Khyber Pakhtunkhwa where sometimes parents prefer males higher education over females. The main factor that is responsible for that is the financial resources of the parents. Further, girl's physical security and risk of lewd behavior stop them to send their girls in colleges and universities.

\section{REFERENCES}

Aezaz, S., \& Kemal, A. (2012). Gender role attitudes and occupational aspirations of Pakistani adolescents. FWU Journal of Social Sciences, 6(1), 89-98.

Ahmad, F. (2001). Modern traditions? British Muslim women and academic achievement. Gender and Education 130, 137-52.

Ali, T. S., Krantz, G., Gul, R., Asad, N., Johansson, E., \& Mogren, I. (2011). Gender roles and their influence on life prospects for women in Urban Karachi, Pakistan: a qualitative study. Global Health Action, 4(1), 1-9.

Andres, A., \& Chavez, E. (2015). Which way out of poverty? The human capital versus human capabilities approaches. Maskana, 6, 19-25.

Ashraf, D. (2007). Shifting position and changing image: Women teachers' experiences in the northern areas of Pakistan. In Gender and education in Pakistan, ed. R. Qureshi and J.F.A. Rarieya, 78-108. Karachi: Oxford University Press.

Awan, S. Z. (2016). Relevance of Education for Women's Empowerment in Punjab, Pakistan. Journal of International Women's Studies, 18(1), 208-229.

Bukhari, F.Y., \& Ramzan, M. (2013). Gender discrimination: a myth or truth women status in Pakistan. IOSR Journal of Business and Management, 8(2), 88-97. 
Bushra, K. (2014). To be a Woman in Pakistan: Stories of Struggle and Survival. In Margaret Alston (Ed.), Gender, Development and Social Change: Women, Political Struggle and Gender Equality in South Asia. New York: Palgrave Macmillian. 59.

Chaudhry, I. S., \& Rahman, S. (2009). The Impact of Gender Inequality in Education on Rural Poverty in Pakistan: An Empirical Analysis. European Journal of Economics, Finance and Administrative Sciences, 4(1) 174-175.

Coleman, M. (2007). Gender and educational leadership in England: A comparison of secondary head teachers' views over time. School Leadership and Management 27(4), 383-399

Ejaz, A., Younis, M., \& Shurgeel, k. (2015). A Review of Rural Women Education in Pakistan. Science International, 27(1), 23-39.

Grunenfelder, J. (2012). Negotiating gender relations: Muslim women and formal employment in Pakistan's rural development. Gender, Work and Organization, 20(6), 599-615.

Haider, S. Z. (2008). Challenges in Higher Education: Special Reference to Pakistan and South Asian Developing Countries. Nonpartisan Education Review, 4(2), 245-265.

Haque, M. (2002). Discrimination starts at home: A brief on parents' aspirations for adolescents and youth in Pakistan. Islamabad: Population Council.

Henard, F., \& Roseveare, D. (2012). Fostering Quality Teaching in Higher Education: Policies and Practices. OECD, IMHE (Program on Institutional Management in Higher Education).

Jamal, A. (2014). Men's perception of women's role and girls' education among Pashtun tribes of Pakistan: A qualitative Delphi study. Cultural and Pedagogical Inquiry, 6(2), 17-34.

Jejeebhoy, S. J., \& Sathar, Z. A. (2001). Women's autonomy in India and Pakistan: the influence of religion and region. Population and Development Review, 27(4), 687-712.

Khan, S. A. (2007). Gender issues in higher education in Pakistan. A study on policy measures and other factors determining girls' education. Islamabad: UNESCO Office.

Madhani, N. (2007). Career development in management at a Pakistani university: Is gender a factor? In Gender and education in Pakistan, ed. R. Qureshi and J.F.A. Rarieya, 216-36. Karachi: Oxford University Press.

Malik, R. (2014). Aid Effectiveness and the Role of Donor Intervention in the Education Sector in Pakistan: A Review of Issues and Literature (No. 6). RECOUP Working Paper.

Malik, S. (2005). Impact of higher education in understanding of social recognition in women. $\mathrm{PhD}$ thesis, University of Arid Agriculture, Rawalpindi, Pakistan.

Naz, A., Hussain, M., Daraz, U., Khan, W., Khan, T., Salman, M., \& Khan, M.S. (2013). A paradigm shift in women's movement and gender reforms in Pakistan (a historical overview). Global Journal of Human, Social Science, Sociology and Culture, 13(1), 21-25.

Psacharopoulos, G., \& Patrinos. H. (2002). Returns to Investment in Education: A Further Update. World Bank Policy Research Working Paper 2881 Washington, D.C.: World Bank.

Qureshi, R., Pirzado, P., \& Nasim, S. (2007). Schooling in rural Sindh, Pakistan. In Gender and education in Pakistan, ed. R. Qureshi and J.F.A. Rarieya, 126-46. Karachi: Oxford University Press.

Rafiq, H. M. W., Fatima, T., Sohail, M. M., Saleem, M., \& Khan, M. A. (2013). Parental involvement and academic achievement; A study on secondary school students of Lahore, Pakistan. International Journal of Humanities and Social Science, 3(8), 223-237.

Ray, R. (2000). Analysis of child labor in Peru and Pakistan: A comparative study. Journal of Population Economics, 13(1), 3-19.

Sadia, S., \& William, A. (2015). Personal and Social Problems Faced by Women in Higher Education. FWU Journal of Social Sciences, 9(2), 35-43.

Samina, M., \& Kathy, C. (2011). Higher education and women's empowerment in Pakistan. Gender and Education, 23(1), 29-45

Shahzad, S., Ali, R., Qadeer, M. Z., \& Khan, M. S. (2011). Community Attitude towards Female Education. International Journal of Academic Research, 3(1), 17-25.

Sofia, I. (2015). Economic Empowerment of women in Pakistan. In Susanne Moore (Ed.), Contemporary Global Perspectives on Gender Economics. Hershey: IGI Global. 132.

Suen, S. (2013). The education of women as a tool in development: challenging the African maxim. Hydra, 1(2), 60-76. 
Sumera, M., Chong, L., \& Hussain, M. (2018). Females Higher Education in Pakistan: An Analysis of Socio-Economic and Cultural Challenges. Advances in Social Sciences Research Journal, 5(6) 379-397.

UNICEF. (2006). Annual Report 2006, ISBN: 978-92-806-4164-6

World Bank (2010) "Education in Sub-Saharan Africa: Policies for Adjustment Revitalization and Expansion"

Zafar, S., Batool, Z., \& Bano, S. (2005). Female participation in decision making process in family matters in district Faisalabad-Pakistan. Journal of Agriculture \& Social Sciences, 1(3), 285287. 